\title{
Transcatheter aortic valve implantation and bleeding: incidence, predictors and prognosis
}

\author{
Thomas Pilgrim • Stefan Stortecky • \\ Fabienne Luterbacher - Stephan Windecker • \\ Peter Wenaweser
}

Published online: 10 November 2012

(c) Springer Science+Business Media New York 2012

\begin{abstract}
Peri-procedural bleeding complications are feared adverse events in patients undergoing transcatheter aortic valve implantation (TAVI). Little is known about the implications of peri-procedural bleeding on clinical outcome. In a prospective single-center registry of consecutive patients undergoing TAVI, we investigated incidence, predictors and clinical consequences of life-threatening and major bleeding as defined by the Valve Academic Research Consortium. Among 389 consecutive patients undergoing TAVI by a transfemoral $(79.2 \%)$, transapical $(19.6 \%)$ or trans-subclavian (1.3\%) approach between July 2007 and October 2011, life-threatening or major peri-procedural bleeding events occurred in $64(16.4 \%)$ and 125 patients $(32.1 \%)$, respectively. Patients with peri-procedural bleeding events had a higher logistic EuroSCORE, more advanced renal disease, and were more symptomatic as assessed by New York Heart Association functional class at baseline as compared to patients with no bleeding. Lifethreatening bleeding was associated with a higher all-cause (17.2 vs 5.6 vs $3.0 \%, p<0.001)$ and cardiovascular mortality (10.9 vs 5.6 vs $2.5 \%, p=0.02)$ at 30 days compared to patients with major bleeding or no bleeding. Multivariate analysis identified transapical access (OR 2.6, $95 \%$ CI 1.4-4.8; $p=0.002$ ), glomerular filtration rate $<30 \mathrm{ml} / \mathrm{min}$ (OR 2.3, $95 \%$ CI 1.1-4.7, $p=0.031$ ), and diabetes (OR 1.8, $95 \%$ CI 1.001-3.2, $p=0.049)$ as
\end{abstract}

T. Pilgrim and S. Stortecky contributed equally to this study.

T. Pilgrim $\cdot$ S. Stortecky $\cdot$ F. Luterbacher $\cdot$ S. Windecker

P. Wenaweser $(\square)$

Department of Cardiology, Swiss Cardiovascular Center,

Bern University Hospital, Bern, Switzerland

e-mail: peter.wenaweser@insel.ch independent predictors of life-threatening, peri-procedural bleeding. Life-threatening bleeding complications in patients undergoing TAVI are associated with increased mortality. Renal impairment, diabetes, and transapical approach were identified as independent risk factors for life-threatening bleeding events.

Keywords Access site complication · Bleeding · TAVI

\section{Introduction}

Transcatheter aortic valve Implantation improves survival in inoperable patients with severe aortic stenosis [1] and is a treatment alternative to surgical aortic valve replacement in patients at high peri-procedural risk [2].

Bleeding complications have been associated with adverse clinical outcome in patients undergoing percutaneous coronary interventions for treatment of coronary artery disease, and are related to access site [3], vascular access sheath diameter, as well as antiplatelet and antithrombotic regimen [4, 5]. TAVI is performed with the use of large vascular access sheaths in case of a transfemoral approach (16-20 French), and requires surgical access in case of transapical and transsublcavian interventions, which increase the risk of bleeding complications. Lifethreatening peri-procedural bleeding as assessed by the Valve Academic Research Consortium (VARC) criteria was observed in up to every fourth patient in recent observational TAVI studies [6-10]. Moreover, bleeding complications were associated with an increased risk of death in the PARTNER A trial comparing TAVI with surgical aortic valve replacement among patients at increased risk (HR 2.11, $95 \%$ CI 1.41-3,17, $p<0.001$ ) [2]. 
The objective of the present study was to investigate the incidence, predictors and implications of peri-procedural bleeding in a prospective single-center TAVI registry.

\section{Methods}

\section{Patient population}

Patients with severe symptomatic aortic stenosis at increased risk for surgical aortic valve replacement were consecutively included in a prospective single-center registry initiated in August 2007. Eligibility for TAVI was discussed in the Heart Team consisting of interventional cardiologists and cardiac surgeons. For an approximate estimate of the surgical risk the logistic EuroScore and the STS score were applied. Patients with valve-in-valve implantation for degenerated aortic bioprostheses were excluded from this analysis. Standard evaluation for eligibility to undergo TAVI included right and left heart catheterization, CT angiography of the aortic root and the peripheral vessels as well as transthoracic and transesophageal echocardiography. Treatment allocation was determined in an interdisciplinary Heart Team discussion and the selection of access site and device were based on anatomical characteristics including peripheral vascular diameter, vascular tortuosity, annular and vessel calcification, and annulus dimension. The registry was approved by the local ethics committee and all subjects gave written, informed consent.

\section{Procedures}

TAVI was performed by transfemoral, transapical or transsubclavian access using the Medtronic CoreValve or the Edwards Sapien Valve as described previously [7]. Transfemoral TAVI was performed in the majority of patients under local anesthesia and conscious sedation. Peri-procedural treatment consisted of unfractionated heparin $(70-100 \mathrm{U} / \mathrm{kg}$ ), aspirin $100 \mathrm{mg} \mathrm{qd}$ and clopidogrel (300 mg loading one day prior to the procedure followed by $75 \mathrm{mg}$ qd for 3-6 months) plus three doses of a prophylactic antibiotic treatment.

\section{Data collection}

Standardized follow-up was performed by clinical visits or telephone interviews at 1 month, 1 year, and yearly thereafter. Clinical adverse events were evaluated by review of medical records and discharge letters collected from treating hospitals, primary care physicians, and cardiologists. All potential adverse events were adjudicated by a clinical event committee of interventional cardiologists and cardiac surgeons.

\section{Definitions}

Clinical endpoints were defined according to the criteria proposed by the Valve Academic Research Consortium (VARC) [11]. Cardiovascular death was defined as any death due to a proximate cardiac cause or death of unknown cause, as well as all procedure-related deaths and death caused by non-coronary vascular conditions such as cerebrovascular disease, pulmonary embolism, or other vascular disease. Peri-procedural myocardial infarction was determined by new ischemic symptoms or signs in the presence of elevated cardiac biomarkers (two or more postprocedure samples that were $>6-8 \mathrm{~h}$ apart with a $20 \%$ increase in the second sample and a peak value exceeding 10x the 99th percentile upper reference limit (URL), or a peak value exceeding $5 \times$ the 99th percentile URL with new pathological $\mathrm{Q}$ waves in at least two contiguous leads) within $72 \mathrm{~h}$ after the index procedure. Major stroke was considered in case of a rapid onset of focal or global neurological deficit of $\geq 24 \mathrm{~h}$ duration requiring therapeutic intervention, or documentation of a new intracranial defect using MRI or CT-scan. Life-threatening or disabling bleeding included [1] bleeding into a critical area or organ such as the pericardial space, or [2] bleeding causing hypovolemic shock or requiring vasopressors or surgery, or [3] bleeding with an overt source of bleeding with a decrease in haemoglobin $\geq 5 \mathrm{~g} / \mathrm{dl}$ or packed red blood cells (PRBC) transfusion $\geq 4$ units. Major bleeding included overt bleeding associated with a decrease in haemoglobin level $\geq 3.0 \mathrm{~g} / \mathrm{dl}$. Access site complications were classified as major in case of access-related vascular injuries leading to either death, need for blood transfusions ( $\geq 4$ units), percutaneous or surgical intervention, or irreversible endorgan damage. Minor vascular complications encompassed failure of percutaneous access site closure resulting in interventional or surgical correction. The modified RIFLE classification (risk, injury, failure, low output, end-stage kidney disease) was used for the definition of kidney injury and was based upon changes in serum creatinine within $72 \mathrm{~h}$ after the procedure. Stage 1 was determined as an increase of serum creatinine to $150-200 \%$ (or an increase of $\geq 26.4 \mu \mathrm{mol} / \mathrm{l}$ ), stage 2 was defined as an increase of baseline creatinine to $200-300 \%$, and stage 3 was diagnosed in case of an increase in creatinine of $\geq 300 \%$ with an acute increase of at least $44 \mu \mathrm{mol} / \mathrm{l}$. Anemia at baseline was defined according to the definition provided by the World Health Organization (WHO) as a haemoglobin concentration of less than $120 \mathrm{~g} / \mathrm{l}$ in female patients and $<130 \mathrm{~g} / \mathrm{l}$ in male patients. 
Statistical analysis

Statistical analyses were performed using SPSS Statistics Version 17.0. Continuous variables are presented as mean \pm standard deviation (SD) and were compared by means of a ANOVA test. Categorical data are expressed as frequency (percentages), and were compared using the Chi-square and Fishers exact tests as appropriate. Survival was estimated using the Kaplan-Meier method. A $p$ value $<0.05$ was considered statistically significant. A multivariate analysis was performed using the following parameters: age, gender, body mass index, diabetes, peripheral vascular disease, renal impairment (glomerular filtration rate $<30 \mathrm{ml} / \mathrm{min}$ ), and type of access.

\section{Results}

Between August 2007 an October 2011, 389 consecutive patients underwent TAVI for severe symptomatic valvular aortic stenosis by transfemoral (79.2\%), transapical $(19.5 \%)$ or trans-subclavian $(1.3 \%)$ access. Bleeding complications were the most common peri-procedural adverse events and occurred in $48.6 \%$ of all patients. Lifethreatening bleeding events were encountered in 64 patients $(16.4 \%)$ and were related to vascular access site complications in $31.3 \%$ of cases. Major bleeding events were observed in 125 patients $(32.1 \%)$ and were associated with access site complications in $20.0 \%$ of cases. Baseline characteristics of patients with and without bleeding complications are summarized in Tables 1 and 2 . Patients with peri-procedural bleeding had a higher logistic EuroSCORE, more advanced renal disease, and were more symptomatic as assessed by New York Heart Association functional class. There was no significant difference with regard to concomitant revascularization procedures (Table 3). Patients with life-threatening bleeding more commonly belonged to the group undergoing TAVI by transapical access (35.9\%) compared to patients with major bleeding $(20.8 \%)$ or no bleeding (13.5\%) $(p=0.006)$. Patients suffering from peri-interventional life-threatening bleeding had a significantly higher allcause (17.2 vs $3.0, p<0.001)$ and cardiovascular mortality (10.9 vs $2.5 \%, p=0.01)$, as well as a trend towards a higher rate of myocardial infarction (3.2 vs $0 \%$, $p=0.057)$ at 30 days compared to patients with no bleeding. Conversely, patients with major bleeding compared to those without bleeding showed no differences in terms of all-cause death (5.6 vs $3.0 \%, p=0.258$ ), cardiovascular death (5.6 vs $2.5 \%, p=0.225$ ), or myocardial infarction (Table 4). In line with an increased peri-procedural risk, patients with life-threatening bleeding had impaired long-term survival during a follow-up period up to three years, which was mainly determined by early events (Fig. 1). In addition, post-interventional renal impairment was more frequently encountered among patients with life-threatening bleeding compared to patients with major or no bleeding (Table 4).

Predictors of life-threatening bleeding were evaluated in a multivariable analysis. Transapical access (OR 2.6, $95 \%$ CI 1.4-4.8; $p=0.002$ ), renal impairment (glomerular filtration rate $<30 \mathrm{ml} / \mathrm{min}$; OR $2.3,95 \%$ CI 1.1-4.7; $p=0.031$ ), and diabetes (OR 1.8, $95 \%$ CI 1.001-3.2; $p=0.049)$ were identified as independent predictors of life-threatening peri-procedural bleeding.

\section{Discussion}

The salient findings of the present study can be summarized as follows: (1) life-threatening peri-procedural bleeding events were observed in $16 \%$ of patients and were related to access site complications in one out of three patients. (2) Peri-interventional life-threatening bleeding was associated with an increased risk of mortality at 30 days. (3) Distinct risk factors which increase the risk of a life-threatening bleeding event include renal impairment, diabetes, and a transapical access route.

Our analysis is in line with the findings of previous studies reporting a high rate of major or life-threatening bleeding complications among patients undergoing TAVI. The incidence of peri-procedural bleeding events according to the VARC criteria was comparable to previous studies reporting rates of life-threatening bleeding between 5 and $26 \%$ and of major bleeding between 2 and $38 \%$ [6, 8-10]. The wide range in bleeding complications across various studies may be related at least in part to small sample size and the lack of independent event adjudication. Of note, the rigorous VARC criteria classify the transfusion of two or more PRBC as major bleeding, which explains to a large extent the high rate of bleeding events found in the present cohort. Especially among patients with anemia at baseline, a strategy to transfuse PRBC prior or only after TAVI will substantially impact on the rate of major bleeding adverse events. Of note, more than $50 \%$ of the overall population had a anemia at baseline and were not prophylactically transfused pre-procedurally.

This explains in part the fact that bleeding events were driven by vascular access site complications in $31 \%$ of the patients with life-threatening bleeding, and in $20 \%$ of the patients with major bleeding events only. Our data do not demonstrate an impact of major bleeding events on clinical outcome with respect to mortality although the number of included patients is too small to conclusively address this issue. Conversely, a life-threatening bleeding complication substantially increased the risk of short-term mortality and 
Table 1 Baseline clinical characteristics

\begin{tabular}{|c|c|c|c|c|c|}
\hline & $\begin{array}{l}\text { Overall } \\
N=389\end{array}$ & $\begin{array}{l}\text { No bleeding } \\
N=200\end{array}$ & $\begin{array}{l}\text { Major bleeding } \\
N=125\end{array}$ & $\begin{array}{l}\text { Life-threat. bleeding } \\
N=64\end{array}$ & $p$ Value \\
\hline Age (years, mean $\pm \mathrm{SD}$ ) & $82.5 \pm 5.8$ & $82.0 \pm 6.1$ & $83.4 \pm 5.1$ & $82.3 \pm 6.0$ & 0.105 \\
\hline Females $(\mathrm{n} / \%)$ & $224 / 57.6$ & $115 / 57.5$ & $69 / 55.2$ & $40 / 62.5$ & 0.630 \\
\hline $\mathrm{BMI}\left(\mathrm{kg} / \mathrm{m}^{2}\right.$, mean $\left.\pm \mathrm{SD}\right)$ & $26.2 \pm 5.1$ & $26.7 \pm 5.2$ & $25.6 \pm 4.9$ & $25.8 \pm 4.8$ & 0.112 \\
\hline \multicolumn{6}{|l|}{ Cardiac risk factors } \\
\hline Hypertension (n/\%) & $303 / 77.9$ & $155 / 77.5$ & $99 / 79.2$ & $49 / 76.6$ & 0.901 \\
\hline Current smoker $(\mathrm{n} / \%)$ & $48 / 12.4$ & $22 / 11.1$ & $20 / 16.0$ & $6 / 9.4$ & 0.306 \\
\hline Diabetes mellitus (n/\%) & $105 / 27.0$ & $51 / 25.5$ & $30 / 24.0$ & $24 / 37.5$ & 0.112 \\
\hline Positive family history $(\mathrm{n} / \%)$ & $73 / 18.8$ & $45 / 22.6$ & $18 / 14.4$ & $10 / 15.6$ & 0.142 \\
\hline Glomerular filtration rate & $52.7 \pm 21.8$ & $56.2 \pm 23.8$ & $48.7 \pm 17.9$ & $43.3 \pm 19.1$ & $<0.001$ \\
\hline Anemia $^{a}$ & $229 / 58.9$ & $124 / 62.0$ & $65 / 52.0$ & $40 / 62.5$ & 0.166 \\
\hline Hemoglobin $(\mathrm{g} / \mathrm{l}$, mean $\pm \mathrm{SD})$ & $121 \pm 16$ & $121 \pm 15$ & $122 \pm 16$ & $119 \pm 17$ & 0.581 \\
\hline Hematocrit $(\% \pm \mathrm{SD})$ & $36 \pm 5$ & $36 \pm 4$ & $36 \pm 5$ & $36 \pm 5$ & 0.645 \\
\hline Thrombocytes before intervention $(\times 109 / 1$, mean \pm SD $)$ & $220 \pm 78$ & $219 \pm 87$ & $219 \pm 64$ & $225 \pm 76$ & 0.866 \\
\hline International normalized ratio (INR) ${ }^{\mathrm{b}}$ & $1.3 \pm 0.3$ & $1.3 \pm 0.3$ & $1.3 \pm 0.2$ & $1.3 \pm 0.3$ & 0.875 \\
\hline \multicolumn{6}{|l|}{ Past medical history } \\
\hline Prior MI $(\mathrm{n} / \%)$ & $61 / 15.7$ & $28 / 14.0$ & $23 / 18.4$ & $10 / 15.6$ & 0.569 \\
\hline Prior PCI $(\mathrm{n} / \%)$ & $94 / 24.2$ & $44 / 22.0$ & $35 / 28.0$ & $15 / 23.4$ & 0.465 \\
\hline $\mathrm{CABG}(\mathrm{n} / \%)$ & $72 / 18.5$ & $35 / 17.5$ & $26 / 20.8$ & $11 / 17.2$ & 0.725 \\
\hline Previous stroke $(\mathrm{n} / \%)$ & $30 / 7.7$ & $17 / 8.5$ & $10 / 8.0$ & $3 / 4.7$ & 0.603 \\
\hline $\operatorname{PVD}(\mathrm{n} / \%)$ & $87 / 22.4$ & $40 / 20.0$ & $34 / 27.2$ & $13 / 20.3$ & 0.289 \\
\hline COPD $(\mathrm{n} / \%)$ & $72 / 18.7$ & $42 / 21.0$ & $21 / 17.2$ & $9 / 14.3$ & 0.432 \\
\hline \multicolumn{6}{|l|}{ Symptoms } \\
\hline NYHA functional class (mean \pm SD) & $2.7 \pm 0.9$ & $2.7 \pm 0.7$ & $2.6 \pm 0.8$ & $2.9 \pm 0.7$ & 0.045 \\
\hline Angina $(\mathrm{n} / \%)$ & $123 / 31.6$ & $65 / 32.5$ & $40 / 32.0$ & $18 / 28.1$ & 0.802 \\
\hline Syncope $(\mathrm{n} / \%)$ & $47 / 12.1$ & $26 / 13.1$ & $11 / 8.8$ & $10 / 15.6$ & 0.333 \\
\hline \multicolumn{6}{|l|}{ Cardiac rhythm } \\
\hline Atrial fibrillation & $103 / 27.0$ & $17 / 26.6$ & $30 / 24.0$ & $56 / 29.2$ & 0.597 \\
\hline Prior pacemaker (n/\%) & $39 / 10.1$ & $19 / 9.5$ & $13 / 10.5$ & $7 / 10.9$ & 0.928 \\
\hline \multicolumn{6}{|l|}{ Risk assessment } \\
\hline Log. EuroSCORE $(\%$, mean \pm SD $)$ & $24.3 \pm 14.2$ & $23.1 \pm 14.4$ & $24.1 \pm 13.2$ & $28.3 \pm 15.0$ & 0.041 \\
\hline STS score $(\%$, mean \pm SD $)$ & $6.8 \pm 5.3$ & $6.3 \pm 5.2$ & $7.3 \pm 5.4$ & $7.4 \pm 5.0$ & 0.155 \\
\hline \multicolumn{6}{|l|}{ Medical treatment } \\
\hline Acetylsalicylic acid (n/\%) & $237 / 61.7$ & $121 / 61.1$ & $76 / 61.3$ & $40 / 64.5$ & 0.884 \\
\hline Clopidogrel (n/\%) & $69 / 18.0$ & $33 / 16.7$ & $28 / 22.6$ & $8 / 12.9$ & 0.213 \\
\hline Oral anticoagulation $(\mathrm{n} / \%)$ & $106 / 27.5$ & $54 / 27.3$ & $32 / 25.8$ & $20 / 31.7$ & 0.686 \\
\hline
\end{tabular}

$M I$ myocardial infarction, $P C I$ percutaneous coronary intervention, $C A B G$ coronary artery bypass graft, $P V D$ peripheral vascular disease, $N Y H A$ New York Heart Association (mean \pm standard deviation), EuroSCORE European System for Cardiac Operative Risk Evaluation, STS society of thoracic surgeons

a According to the WHO definition ( $120 \mathrm{mg} / \mathrm{l}$ for women and $<130 \mathrm{mg} / \mathrm{l}$ for men)

b Among patients under oral anticoagulation only

therefore requires careful attention. A meticulous screening for the evaluation of the optimal access site is of paramount importance. For instance, in a transfemoral case with heavily calcified arteries, a surgical cut-down may be considered instead of a pure percutaneous approach. To facilitate closure of the access site a technique of provisional balloon occlusion of the iliofemoral axis might reduce the risk of access site bleeding substantially [12].

Similar to our own experience, an analysis focusing on bleeding complications in the PARTNER A trial revealed a twofold increased risk of death for patients with bleeding events [2]. Several reasons may account for the adverse 
Table 2 Baseline characteristics II

\begin{tabular}{|c|c|c|c|c|c|}
\hline & $\begin{array}{l}\text { Overall } \\
N=389\end{array}$ & $\begin{array}{l}\text { No bleeding } \\
N=200\end{array}$ & $\begin{array}{l}\text { Major bleeding } \\
N=125\end{array}$ & $\begin{array}{l}\text { Life-threat. bleeding } \\
N=64\end{array}$ & $\overline{p \text { Value }}$ \\
\hline $\operatorname{LVEF}(\%$, mean $\pm \mathrm{SD})$ & $52 \pm 15$ & $52 \pm 15$ & $52 \pm 15$ & $51 \pm 14$ & 0.967 \\
\hline Mean gradient $(\mathrm{mmHg}$, mean $\pm \mathrm{SD})$ & $44 \pm 17$ & $44 \pm 17$ & $46 \pm 16$ & $41 \pm 16$ & 0.241 \\
\hline $\operatorname{AVA}\left(\mathrm{cm}^{2}\right.$, mean $\left.\pm \mathrm{SD}\right)$ & $0.6 \pm 0.2$ & $0.6 \pm 0.2$ & $0.6 \pm 0.2$ & $0.6 \pm 0.2$ & 0.239 \\
\hline Coronary artery disease $(\mathrm{n} / \%)$ & $247 / 63.5$ & $121 / 60.5$ & $84 / 67.2$ & $42 / 65.6$ & 0.441 \\
\hline PAS pressure $(\mathrm{mmHg}$, mean $\pm \mathrm{SD})$ & $51 \pm 17$ & $50 \pm 16$ & $51 \pm 18$ & $54 \pm 18$ & 0.254 \\
\hline
\end{tabular}

$L V E F$ left ventricular ejection fraction, $A V A$ aortic valve area, $P A S$ pulmonary artery systolic pressure

Table 3 Procedural characteristics

\begin{tabular}{lllll}
\hline & $\begin{array}{l}\text { Overall } \\
N=389\end{array}$ & $\begin{array}{l}\text { No bleeding } \\
N=200\end{array}$ & $\begin{array}{l}\text { Major bleeding } \\
N=125\end{array}$ & $\begin{array}{l}\text { Life-threat. bleeding } \\
N=64\end{array}$ \\
\hline $\begin{array}{l}\text { Revascularization } \\
\text { Concomitant PCI }\end{array}$ & & & $12 / 18.8$ \\
Staged PCI & $63 / 16.2$ & $29 / 14.5$ & $11 / 17.6$ & 0.824 \\
Aortic valve implantation & $35 / 9.0$ & $19 / 9.5$ & $12 / 9.6$ & 25.3 \\
Transfemoral MCV (n/ \%) & & & & 0.006 \\
Trans-subclavian MCV (n/ \%) & $5 / 1.3$ & $122 / 61.0$ & $73 / 58.4$ & $1 / 1.6$ \\
Transfemoral ES (n/ \%) & $88 / 22.6$ & $49 / 24.5$ & $2 / 1.6$ & $15 / 23.4$ \\
Transapical ES (n/ \%) & $76 / 19.5$ & $27 / 13.5$ & $24 / 19.2$ & $23 / 35.9$ \\
\hline
\end{tabular}

$M C V$ Medtronic CoreValve bioprosthesis, ES Edwards Sapien bioprosthesis, PCI percutaneous coronary intervention

Table 4 Clinical outcome at 30 days

\begin{tabular}{lllll}
\hline & $\begin{array}{l}\text { Overall } \\
N=389\end{array}$ & $\begin{array}{l}\text { No bleeding } \\
N=200\end{array}$ & $\begin{array}{l}\text { Major bleeding } \\
N=125\end{array}$ & $\begin{array}{l}\text { Life-threat. bleeding } \\
N=64\end{array}$ \\
\hline All cause mortality (n/ \%) & $24 / 6.2$ & $6 / 3.0$ & $7 / 5.6$ & $22 / 17.2$ \\
Cardiovascular mortality (n/ \%) & $19 / 4.9$ & $5 / 2.5$ & $7 / 5.6$ & $7 / 10.9$ \\
Myocardial infarction (n/ \%) & $2 / 0.5$ & $0 / 0$ & $0 / 0$ & $2 / 3.2$ \\
Major stroke (n/ \%) & $14 / 3.7$ & $7 / 3.6$ & $6 / 4.9$ & $1 / 1.6$ \\
Access-site related complications & & & & 0.022 \\
Major (n/ \%) & $30 / 7.7$ & $6 / 3.0$ & $8 / 6.4$ & 0.006 \\
Minor (n/ \%) & $42 / 10.8$ & $21 / 10.5$ & $17 / 13.6$ & $4 / 6.3$ \\
Valve-related re-interventions & $8 / 2.1$ & $4 / 2.0$ & $2 / 1.6$ & $3 / 3.1$ \\
Number of PRBC (n, mean \pm SD) & $1.1 \pm 2.3$ & $0.1 \pm 0.4$ & $0.9 \pm 1.0$ & $4.4 \pm 4.2$ \\
Renal failure & & & & 0.534 \\
RIFLE stage 1 (n/ \%) & $44 / 11.3$ & $15 / 7.5$ & $15 / 12.0$ & $14 / 21.9$ \\
RIFLE stage 2 (n/ \%) & $5 / 1.3$ & $3 / 1.5$ & $1 / 0.8$ & $1 / 1.6$ \\
RIFLE stage 3 (n/ \%) & $15 / 3.9$ & $4 / 2.0$ & $2 / 1.6$ & $9 / 14.1$ \\
\hline
\end{tabular}

RIFLE risk, injury, failure, loss, end-stage kidney disease, $P R B C$ packed red blood cells

outcome of these patients: first, life-threatening bleeding might induce prolonged ischemia and hypotension resulting in end organ damage. Second, bleeding due to severe vascular access complications may require bailout interventions with their associated risks. Third, bleeding per se is known as surrogate marker for adverse clinical outcome as evidenced in previous PCI studies [13]. Forth, nonaccess related bleeding events such as intracranial, upper gastrointestinal or retroperitoneal bleeding events may have deleterious consequences. Fifth, the adverse outcome 


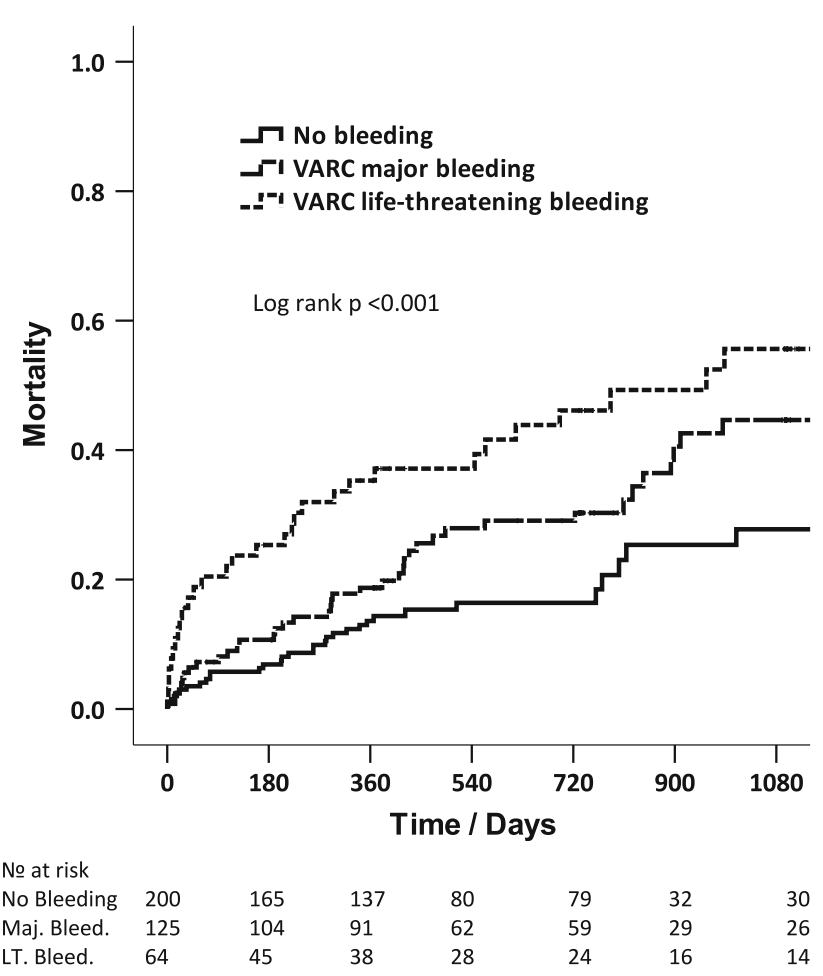

Fig. 1 Long-term mortality as a function of peri-procedural bleeding

may be related to the discontinuation of antiplatelet and antithrombotic treatment. Finally, blood transfusions per se are known to impact adversely on clinical outcome.

The multivariate analysis identified predictors for bleeding like renal impairment which has been established as a risk factor for bleeding also in patients undergoing PCI which may be related to impaired platelet function [14]. Diabetic patients might be at increased risk of vascular access site complications due to smaller vessel diameter and more diffuse vessel disease. The transapical access which requires a lateral thoracotomy and opening of the thorax as well as the use of very large introducer sheaths is accompanied by higher risk of blood loss and transfusion. Transapical access can be understood as a surrogate for peripheral vascular disease and may mask the risk of bleeding associated with peripheral vascular disease in case of a transfemoral access. Last but not least, clinical experience demonstrates that the risk of bleeding has been reduced with the introduction of smaller sheath sizes and growing experience of the operators.

Rates of life-threatening and major bleeding across groups according to antithrombotic and antiplatelet regimen (single antiplatelet therapy only, vitamin $\mathrm{K}$ antagonist only, dual antiplatelet therapy, antiplatelet therapy in combination with vitamin $\mathrm{K}$ antagonist) did not show any significant difference. This may be attributable to several underlying reasons: First, numbers of patients in each group and numbers of events are modest. Second, the individual treatment regimen was not randomly allocated and is subject to a selection bias. And finally, the rates of bleeding were not adjusted for other risk factors for bleeding events.

\section{Conclusion}

Anemia at baseline is a common finding in TAVI patients. Life-threatening bleeding complications but not major bleeding events according to VARC are associated with increased mortality. Renal impairment, diabetes, and transapical approach were identified as independent risk factors for life-threatening bleeding events.

Disclosures Drs. Windecker and Wenaweser are Proctors for Medtronic CoreValve and Edwards Lifesciences. Supported by an unrestricted research grant of Medtronic to the University of Berne.

\section{References}

1. Makkar RR, Fontana GP, Jilaihawi H, Kapadia S, Pichard AD, Douglas PS, Thourani VH, Babaliaros VC, Webb JG, Herrmann HC, Bavaria JE, Kodali S, Brown DL, Bowers B, Dewey TM, Svensson LG, Tuzcu M, Moses JW, Williams MR, Siegel RJ, Akin JJ, Anderson WN, Pocock S, Smith CR, PARTNER Trial Investigators (2012) Transcatheter aortic-valve replacement for inoperable severe aortic stenosis. N Engl J Med 366(18):1696-1704

2. Kodali SK, Williams MR, Smith CR, Svensson LG, Webb JG, Makkar RR, Fontana GP, Dewey TM, Thourani VH, Pichard AD, Fischbein M, Szeto WY, Lim S, Greason KL, Teirstein PS, Malaisrie SC, Douglas PS, Hahn RT, Whisenant B, Zajarias A, Wang D, Akin JJ, Anderson WN, PARTNER Trial Investigators (2012) Two-year outcomes after transcatheter or surgical aorticvalve replacement. N Engl J Med 366(18):1686-1695

3. Jolly SS, Yusuf S, Cairns J, Niemelä K, Xavier D, Widimsky P, Budaj A, Niemelä M, Valentin V, Lewis BS, Avezum A, Steg PG, Rao SV, Gao P, Afzal R, Joyner CD, Chrolavicius S (2011) RIVAL trial group. Radial versus femoral access for coronary angiography and intervention in patients with acute coronary syndromes (RIVAL): a randomised, parallel group, multicentre trial. Lancet 377(9775):1409-1420

4. Wallentin L, Becker RC, Budaj A, Cannon CP, Emanuelsson H, Held C, Horrow J, Husted S, James S, Katus H, Mahaffey KW, Scirica BM, Skene A, Steg PG, Storey RF, PLATO Investigators, Freij A, Thorsén M (2009) Ticagrelor versus clopidogrel in patients with acute coronary syndromes. N Engl J Med 361(11):1045-1057

5. Wiviott SD, Braunwald E, McCabe CH, Montalescot G, Ruzyllo W, Gottlieb S, Neumann FJ, Ardissino D, De Servi S, Murphy SA, Riesmeyer J, Weerakkody G, Gibson CM, TRITON-TIMI 38 Investigators (2007) Prasugrel versus clopidogrel in patients with acute coronary syndromes. N Engl J Med 357(20):2001-2015

6. Nuis RJ, van Mieghem NM, van der Boon RM, van Geuns RJ, Schultz CJ, Oei FB, Galema TW, Raap GB, Koudstaal PJ, Geleijnse ML, Kappetein AP, Serruys PW, de Jaegere PP (2011) Effect of experience on results of transcatheter aortic valve implantation using a Medtronic CoreValve System. Am J Cardiol 107(12):1824-1829

7. Wenaweser P, Pilgrim T, Roth N, Kadner A, Stortecky S, Kalesan B, Meuli F, Büllesfeld L, Khattab AA, Huber C, Eberle B, 
Erdös G, Meier B, Jüni P, Carrel T, Windecker S (2011) Clinical outcome and predictors for adverse events after transcatheter aortic valve implantation with the use of different devices and access routes. Am Heart J 161(6):1114-1124

8. Buchanan GL, Chieffo A, Montorfano M, Maisano F, Latib A, Godino C, Cioni M, Gullace MA, Franco A, Gerli C, Alfieri O, Colombo A (2011) The role of sex on VARC outcomes following transcatheter aortic valve implantation with both Edwards SAPIEN $^{\mathrm{TM}}$ and Medtronic CoreValve ReValving System ${ }^{\circledR}$ devices: the Milan registry. EuroIntervention 7(5):556-563

9. Mussardo M, Latib A, Chieffo A, Godino C, Ielasi A, Cioni M, Takagi K, Davidavicius G, Montorfano M, Maisano F, Carlino M, Franco A, Covello RD, Spagnolo P, Grimaldi A, Alfieri O, Colombo A (2011) Periprocedural and short-term outcomes of transfemoral transcatheter aortic valve implantation with the Sapien XT as compared with the Edwards Sapien valve. JACC Cardiovasc Interv 4(7):743-750

10. Gurvitch R, Toggweiler S, Willson AB, Wijesinghe N, Cheung A, Wood DA, Ye J, Webb JG (2011) Outcomes and complications of transcatheter aortic valve replacement using a balloon expandable valve according to the Valve Academic Research Consortium (VARC) guidelines. EuroIntervention 7(1):41-48

11. Leon MB, Piazza N, Nikolsky E, Blackstone EH, Cutlip DE, Kappetein AP, Krucoff MW, Mack M, Mehran R, Miller C,
Morel MA, Petersen J, Popma JJ, Takkenberg JJ, Vahanian A, van Es GA, Vranckx P, Webb JG, Windecker S, Serruys PW (2011) Standardized endpoint definitions for transcatheter aortic valve implantation clinical trials: a consensus report from the Valve Academic Research Consortium. J Am Coll Cardiol 57(3):253-269

12. Sharp AS, Michev I, Maisano F, Taramasso M, Godino C, Latib A, Denti P, Dorigo E, Giacomini A, Iaci G, Manca M, Ielasi A, Montorfano M, Alfieri O, Colombo A (2010) A new technique for vascular access management in transcatheter aortic valve implantation. Catheter Cardiovasc Interv 75(5):784-793

13. Spencer FA, Moscucci M, Granger CB, Gore JM, Goldberg RJ, Steg PG, Goodman SG, Budaj A, FitzGerald G, GRACE Investigators (2007) Does comorbidity account for the excess mortality in patients with major bleeding in acute myocardial infarction? Circulation 116:2793-2801

14. Mezzano D, Tagle R, Panes O, Pérez M, Downey P, Muñoz B, Aranda E, Barja P, Thambo S, González F, Mezzano S, Pereira J (1996) Hemostatic disorder of uremia: the platelet defect, main determinant of the prolonged bleeding time, is correlated with indices of activation of coagulation and fibrinolysis. Thromb Haemost 76(3):312-321 